\title{
Plântulas de gergelim cv. BRS seda sob aplicação de água salinizada
}

\section{Sesame seedlings cv. BRS Seda under saline water application}

\author{
Mailson Araújo Cordão ${ }^{(1)}$; Thiago Galvão Sobrinho ${ }^{\left(D^{2}\right.}$; Kyonelly Queila Duarte Brito Andrade ${ }^{\left(D^{3} \text {; }\right.}$ \\ Austro José Faustino Tavares ${ }^{\left(\mathbb{D}{ }^{4}\right.}$; Ronaldo do Nascimento ${ }^{5}$
}

${ }^{1}$ Mestre em Engenharia Agrícola, Universidade Federal de Campina Grande, Campina Grande, Paraíba; +5583996300104; e-mail: mailson.cordao@ gmail.com. ${ }^{2}$ Mestre em Engenharia Agrícola; Universidade Federal de Campina Grande, Campina Grande, Paraíba; e-mail: tgs_galvao@hotmail.com. ${ }^{3}$ Mestre em Engenharia Agrícola, Universidade Federal de Campina Grande, Campina Grande, Paraíba; e-mail: queiladuarte@ hotmail.com. ${ }^{4}$ Graduação em Engenharia Agrícola em Universidade Federal de Campina Grande, Campina Grande, Paraíba; e-mail: engenheiroaustro@gmail.com. ${ }^{5}$ Doutorado em Ciências Agrárias (Fisiologia Vegetal) Universidade Federal de Viçosa, Viçosa, Minas Gerais; e-mail: ronaldon453@gmail.com

\section{$\mathrm{NOT} \mathrm{A}$}

Recebido: $11 / 02 / 2020$

Aprovado: 19/06/2020

\section{Palavras-chave:}

Sesamum indicum L.

Qualidade de água

Estresse salino

\begin{abstract}
R E S U M O
O gergelim é uma importante cultura oleaginosa e alimentícia, bem adaptada às condições da região semiárida, na qual o problema da salinidade é comum. Assim, objetivou-se com este estudo avaliar a germinação e o crescimento das plântulas de gergelim submetidas ao estresse salino. Os tratamentos foram arranjados em delineamento inteiramente casualizado, aplicando cinco tratamentos, sendo os níveis de sais correspondente ás condutividades elétricas da água $\left(0,6 ; 1,2 ; 1,8 ; 2,4\right.$ e $\left.3,0 \mathrm{dS} \mathrm{m} \mathrm{m}^{-1}\right)$ na cultivar de gergelim BRS seda, distribuídos em quatro repetições, totalizando 20 unidades experimentais. As variáveis analisadas foram à porcentagem, a primeira contagem, o índice de velocidade, o tempo médio de germinação, e as variáveis de crescimento das plântulas: comprimento total da plântula, do hipocótilo, da radícula primária, vigor e a massa fresca total da parte área e da radícula primária. Os resultados obtidos denotam que o aumento da salinidade na água ocasiona redução na germinação e no crescimento inicial das plântulas de gergelim. Não é recomendado uso da água com concentrações de sais a partir de $1,2 \mathrm{dS} \mathrm{m} \mathrm{m}^{-1}$ no estabelecimento da cultivar BRS seda.
\end{abstract}

A B S T R A C T
Sesame is an important oil and food crop, well adapted to semi-arid conditions, where a
salinity problem or problem is common. Thus, the objective of this study was to evaluate
the germination and growth of sesame seedlings submitted to salt stress. The treatments
were arranged in a completely randomized design, applying five treatments, with the levels
of salts corresponding to the electrical conductivities of the water $(0.6 ; 1.2 ; 1.8 ; 2.4$ and 3.0
$\left.\mathrm{dS} \mathrm{m}^{-1}\right)$ in the BRS Seda sesame cultivar, distributed in four replications, totaling 20
experimental units. The variables analyzed were the percentage, the first count, the speed
index, average germination time, and seedling growth variables: total seedling length,
hypocotyl, primary root, vigor and total fresh mass of the area and primary root. The results
obtained show that the increase in salinity in the water causes a reduction in the germination
and in the initial growth of the sesame seedlings. It is not recommended to use water with
salt concentrations from $1.2 \mathrm{dS} \mathrm{m} \mathrm{m}^{-1}$ in the establishment of the BRS Seda cultivar.

Key words:

Sesamum indicum L.

Water quality

Saline stress

\section{INTRODUÇÃO}

O gergelim (Sesamum indicum L.) é a oleaginosa mais antiga utilizada pela humanidade, está entre a nona mais cultivada no mundo, devido grande potencial econômico (MESQUITA, et al., 2013). Tem sua origem na Índia, sendo uma cultura de clima tropical, cultivada em quase todos os países (AZEVEDO et al., 2003), devido à importância comercial de suas sementes, na indústria de alimentos e produção de óleo. Os países maiores produtores são Sudão,
Myanmar e Índia com 981,000, 768,858 e 746,000 toneladas respectivamente, o Brasil apresenta uma produtividade média de $7000 \mathrm{~kg} \mathrm{ha}^{-1}$, obtendo uma produção de 14,000 toneladas em uma área colhida de 20,000 hectares (FAOSTAT, 2018).

Essa cultura apresenta característica de resistência à seca, podendo ser cultivada com precipitações mínimas de $300 \mathrm{~mm}$ bem distribuídos, contudo, precipitações entre $500 \mathrm{~mm}$ e 650 $\mathrm{mm}$ é considerada a faixa ótima (GRILO JUNIOR; AZEVEDO, 2013). Nesse sentido, a cultura se torna uma

$\begin{array}{lc}\text { Revista Verde } & \text { v. } 15, \text { n.3, jul.-set., p.319-324, } 2020 \\ \text { ISSN 1981-8203 } & \text { doi: } 10.18378 / \text { rvads.v15i3.7667 } \\ \text { Pombal, Paraíba, Brasil } & \end{array}$

Pombal, Paraíba, Brasil 
importante alternativa para o semiárido Brasileiro onde ocorre baixa precipitação pluvial.

O gergelim é cultivado, principalmente, em pequenas propriedades no semiárido Brasileiro, onde o clima é quente e seco, a evapotranspiração potencial excede a precipitação durante a maior parte do ano, nessas regiões a ocorrência de águas salinas é comum (HOLANDA et al., 2016; DIAS et al., 2018). De acordo com Andréo-Souza et al. (2010), nessas regiões o excesso de sais tanto no solo como na água de irrigação limitam a produção agrícola, causando prejuízos nos cultivos. Esse problema quando combinado com altas taxas de evaporação durante a maior parte do ano, aumenta os riscos de salinização do solo, especialmente, em condições de drenagem deficientes (SUASSUNA et al., 2017). Os sais não são lixiviados e se acumulam no solo afetando a germinação e o crescimento das plantas (LIMA et al., 2015).

A água com característica salobra utilizada na irrigação promove o acúmulo de sais no solo e afeta o rendimento da cultura. No entanto, o primeiro efeito nocivo causado pelos sais ocorre na germinação (FURTADO et al., 2007). Os efeitos negativos do excesso de sais solúveis são devido à elevação do potencial osmótico e a toxidez dos elementos como o $\mathrm{Na}^{+}$e o $\mathrm{Cl}^{-}$. Desse modo, a análise da germinação sobre essas condições serve com um indicativo de tolerância da espécie a salinidade (GUIMARÃES et al., 2013).

Os sais na solução do solo afetam o seu potencial hídrico, pois ocorre a redução do gradiente de potencial entre o solo e a superfície da semente, o que interfere negativamente na captação de água pela semente (POSSAS et al., 2014), causando efeitos altamente significativos sob condições de salinidade (ANDRÉO-SOUZA et al., 2010). O estudo dos efeitos da salinidade na cultura do gergelim é bem explorado na literatura, mas resultados do efeito em algumas cultivares e nas plântulas são escassos. Diante do exposto, objetivou-se com esse estudo avaliar o efeito de diferentes concentrações de sais na água de irrigação sob a germinação e o crescimento inicial das plântulas de gergelim BRS seda.

\section{MATERIAL E MÉTODOS}

O experimento foi desenvolvido em novembro de 2019, no Laboratório de Fisiologia pertencente à Unidade Acadêmica de Engenharia Agrícola, do Centro de Tecnologia e Recursos Naturais da Universidade Federal de Campina Grande(UFCG), em Campina Grande, Paraíba. Os tratamentos foram dispostos em delineamento inteiramente casualizado, os quais corresponderam a cinco níveis de condutividades elétrica da água $\left(\mathrm{CEa}=0,6 ; 1,2 ; 1,8 ; 2,4\right.$ e $\left.3,0 \mathrm{dS} \mathrm{m} \mathrm{m}^{-1}\right)$ com quatro repetições, totalizando 20 unidades experimentais.

Cada repetição foi composta por 50 sementes de gergelim cv. BRS seda, distribuídas uniformemente entre duas folhas de papel Germitest ${ }^{\circledR}$ umedecidas com água de abastecimento (controle) ou solução salina conforme o tratamento, na proporção de 2,5 vezes a massa do papel Germitest ${ }^{\circledR}$ seco. As folhas de papel foram transformadas em rolos e embaladas em sacos plásticos, para evitar a perda da umidade, e colocadas para germinar em câmara de Demanda Bioquímica de Oxigênio (B.O.D.), a $25^{\circ} \mathrm{C}$ na ausência de luz. As sementes foram consideradas germinadas quando a raiz primária foi maior ou igual a 2,0 $\mathrm{mm}$.

Utilizou-se semente da cultiva de gergelim BRS seda desenvolvida pela Embrapa algodão, apresenta as seguintes características agronômicas: tolerância às principais doenças da cultura; porte médio a alto; hábito de crescimento ramificado; ciclo precoce de menos de noventa dias; sementes de coloração branca; teor de óleo entre 50 e $53 \%$ do peso de suas sementes e maior valor comercial, principalmente para indústrias de alimento.

As soluções foram preparadas de modo a corresponder uma proporção equivalente de 7:2:1, entre $\mathrm{Na}: \mathrm{Ca}: \mathrm{Mg}$, respectivamente, a partir dos sais $\mathrm{NaCl}$, $\mathrm{CaCl}_{2} \cdot 2 \mathrm{H}_{2} \mathrm{O}$ e $\mathrm{MgCl}_{2} \cdot 6 \mathrm{H}_{2} \mathrm{O}$, na água de abastecimento $(0,6 \mathrm{dS}$ $\mathrm{m}^{-1}$ ), até atingir as condutividades elétricas de 1,$2 ; 1,8 ; 2,4$ e $3,0 \mathrm{dS} \mathrm{m}^{-1}$, essa relação é predominante aos íons em fontes de água utilizada para irrigação, em pequenas propriedades do Nordeste brasileiro (MEDEIROS, 1992).

As sementes germinadas foram registradas do terceiro ao sexto dia após o início do teste (BRASIL, 2009). Analisandose a porcentagem de germinação (GER \%), a primeira contagem de germinação (PCG\%), o índice de velocidade de germinação (IVG), o tempo médio de germinação (TMG).

A porcentagem de germinação: Corresponde o total de plântulas normais germinadas até o sexto dia de contagem de padrão de germinação (Equação 1).

$\mathrm{GER}=(\mathrm{n} \div \mathrm{N}) \times 100$

Em que, $\mathrm{n}=$ número de sementes germinadas e $\mathrm{N}=$ número total de sementes.

A Primeira contagem de germinação: Correspondente à porcentagem de plântulas normais quantificadas no primeiro dia de contagem, realizada no terceiro dia do teste padrão de germinação (Equação 2).

$\mathrm{PCG}=(\mathrm{n} 1 \times 100) \div \mathrm{N}$

Em que, $n 1=$ número de sementes germinadas no primeiro dia de contagem e $\mathrm{N}=$ número total de sementes.

O índice de velocidade de germinação: Determinado juntamente com o teste de germinação, por contagens diárias de plântulas normais ao longo da duração do teste de germinação, calculado pela fórmula proposta por Maguire (1962), conforme Equação (3).

$$
\mathrm{IVG}=\mathrm{n} 1 \div \mathrm{D} 1+\mathrm{n} 2 \div \mathrm{D} 2+\ldots \mathrm{n} \div \mathrm{D}
$$

Em que, $\mathrm{n}=\mathrm{o}$ número de sementes germinadas em cada dia da contagem e $\mathrm{D}=$ número de dias do início da aplicação dos tratamentos.

O tempo médio de germinação: Determinado juntamente com o teste de germinação, por contagens diárias de plântulas normais ao longo da duração do teste de germinação, de acordo com a Equação (4).

$\mathrm{TMG}=\mathrm{n} 1 \times \mathrm{D} 1+\mathrm{n} 2 \times \mathrm{D} 2+\ldots \mathrm{n} \times \mathrm{D} \div \mathrm{NT}$

Em que, $\mathrm{n}=$ número de sementes germinadas em cada dia; $\mathrm{D}=$ número de dias do início da aplicação dos tratamentos e NT= total de sementes germinadas.

Ao sétimo dia após o início da aplicação dos tratamentos, foram analisadas 10 plântulas normais escolhidas aleatoriamente de cada repetição dos tratamentos obtendo as variáveis de crescimento: o comprimento total da plântula (CTP), do hipocótilo $(\mathrm{CTH})$ e da radícula primária (CPR), utilizando-se uma régua, com resultados expressos em $\mathrm{cm}$ por planta. Também foi analisada a massa fresca da parte total área 
(hipocótilo + cotiledôneos) (MFA) e da radícula primária das plântulas (MFR), pesadas em balança analítica (precisão de $0,01 \mathrm{~g}$ ), expressa em $\mathrm{g}$ por planta.

$\mathrm{O}$ vigor da plântula (VP) foi obtido através do produto entre a porcentagem de germinação e comprimento total das plântulas (ANUPAMA et al., 2014) por meio da Equação (5).

\section{$\mathrm{VP}=\mathrm{CTP} \times \mathrm{GER}$}

Em que: $\mathrm{CTP}=$ comprimento total das plântulas $(\mathrm{cm})$ e $\mathrm{GER}=$ germinação de sementes $(\%)$.

Os dados obtidos foram submetidos à análise de variância pelo teste ' $F$ ' a $5 \%$ de probabilidade e nos casos de significância, realizou-se regressão linear e quadrática, selecionando o modelo em função de sua significância biológica e coeficiente de determinação $\left(\mathrm{R}^{2}\right)$ utilizando-se o software Sisvar 5.3 (FERREIRA, 2011).

\section{RESULTADOS E DISCUSSÃO}

As soluções salinas afetaram o processo de germinação das sementes de gergelim BRS Seda (Figura 1), reduzindo à medida que ocorre os incrementos dos sais na água as variáveis: porcentagem de germinação (GER\%), porcentagem da primeira contagem (PCG), índice de velocidade (IVG) e tempo médio de germinação $(\mathrm{p} \leq 0,01)$. Os efeitos mais acentuados nas variáveis são observado nas maiores condutividades elétricas 2,4 e 3,0 dS m${ }^{-1}$. Esse efeito pode estar relacionado ao aumento dos sais no citoplasma, o que inibe a atividade enzimática em várias vias metabólicas (PRISCO et al., 2016).

Figuras 1. Regressão para porcentagem (CV: 15,40\%) (A), primeira contagem (CV: 10,45\%) (B) e índice de velocidade de germinação (CV: 9,89\%) (C), do gergelim cv. BRS seda em função da água salinizadas.

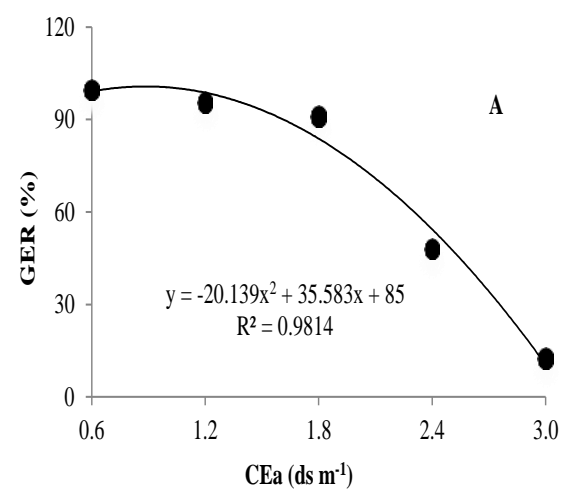

A porcentagem de germinação sob condutividade elétrica

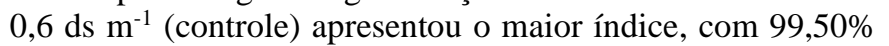
total de sementes germinadas. As condutividades 1,$2 ; 1,8 ; 2,4$ e 3,0 dS m$~^{-1}$ apresentaram reduções de 4,02, 8,54, 51,75 e 87, $43 \%$, respectivamente, em relação ao controle (Figura 1A). Resultados semelhantes foram encontrados por Azevedo et al. (2003) e Bahrami e Razmjoo (2012), quando analisaram o efeito da salinidade na água de irrigação sob cultivares de gergelim, observaram que o aumento da salinidade promoveu redução no percentual de germinação em todas as cultivares utilizadas. O estresse salino interfere na captação de água, resultando em déficit hídrico, como também pode ocorrer a morte devido à toxicidade iônica (BEKELE et al., 2017).

Analisando a primeira contagem e índice de velocidade de germinação (Figuras 1B e 1C), verifica-se que as condutividades 2,4 e $3,0 \mathrm{dS} \mathrm{m}^{-1}$ apresentaram reduções significativas. Esses resultados corroboram com Dias et al. (2017), quando observaram o incremento da salinidade reduziu o percentual de emergência de plântulas normais e o índice de velocidade de emergência da cultivar de gergelim CNPA G3. Consequentemente durante o processo de embebição e início da germinação da semente, altas concentrações de sais reduz o potencial osmótico retendo a água, além da ação dos íons sobre o protoplasma, alterando o metabolismo e o desenvolvimento do tecido embrionário, assim as altas concentrações de sais na solução (POSSAS et al., 2014).

Esses danos são devidos o estresse salino limita a absorção da água pela semente e provoca efeitos tóxicos, podendo causar a morte do embrião, além de promover a ação dos íons sobre o protoplasma da semente (ANDRÉO-SOUZA et al., 2010; SANTOS et al., 2016).

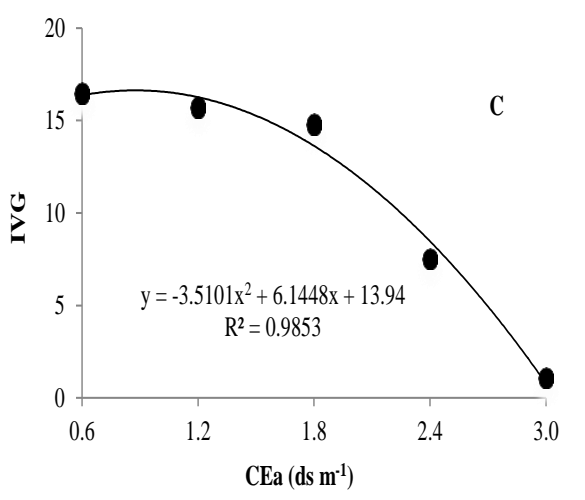

No crescimento das plântulas de gergelim os efeitos dos incrementos dos sais na água, observa-se redução em todas as variáveis $(\mathrm{p} \leq 0,01)$ (Figura 2$)$, sendo mais acentuado do que observado nas variáveis de germinação. Colaborando com resultados Abbasdokht et al. (2012) afirmam que o crescimento inicial do gergelim é prejudicado sob efeitos dos níveis de sais na água.

A redução no crescimento das plântulas de gergelim em função do aumento da salinidade na água é mais evidente a partir da condutividade elétrica $1,8 \mathrm{dS} \mathrm{m}{ }^{-1}$, semelhante ao observado nas variáveis de germinação. De acordo com Soltani et al. (2006), o estrese salino geralmente reduz a capacidade de mobilização da reserva das sementes, reduzindo o crescimento das plântulas.

O comprimento total da plântula é afetado pelos sais de forma linear decrescente (Figura 2A), as condutividades elétricas $1,2 \mathrm{dS} \mathrm{m}{ }^{-1} ; 1,8 \mathrm{dS} \mathrm{m}{ }^{-1} ; 2,4 \mathrm{dS} \mathrm{m} \mathrm{m}^{-1}$ e $3,0 \mathrm{dS} \mathrm{m}{ }^{-1}$ apresentaram reduções de 22,03, 58,00, 75,33 e 94,11\% respectivamente, em relação da condutividade de $0,6 \mathrm{dS} \mathrm{m}^{-1}$ (controle). As plântulas sob a condutividade $3,0 \mathrm{dS} \mathrm{m}^{-1}$ apresentaram apenas a radícula, justificando o baixo valor no crescimento total. Resultados semelhantes foram encontrados por Dias et al. (2017) e Bekele et al. (2017), observaram redução no crescimento do gergelim a medida que ocorre incremento de sais na água, registrando menor altura nas plantas irrigadas com maior salinidade.

Conforme observado na Figura $2 \mathrm{C}$, a radícula apresentou maior média na condutividade de $0,6 \mathrm{dS} \mathrm{m} \mathrm{m}^{-1}(2,55 \mathrm{~cm})$, reduzido com aumento da condutividade elétrica da água, e apresentou o menor resultado $(0,2 \mathrm{~cm})$ na condutividade $3,0 \mathrm{dS}$ $\mathrm{m}^{-1}$. 
Observa-se o efeito mais acentuado no comprimento do hipocótilo (Figura 2B) e menor no comprimento da radícula (Figura 2C). Bahrami e Razmjoo (2012) também constataram que o comprimento da radícula e o comprimento do hipocótilo diminuíram significativamente com o aumento da condutividade elétrica da água, e, o comprimento do hipocótilo foi mais sensível à salinidade da água que o comprimento da radícula.

Figura 2. Efeitos das águas salinizadas sobre o comprimento da plântula (CV: 11,30) (A), do hipocótilo (CV: 15,64) (B), da radícula CV: 15,56 (C) e virgo das plântulas (CV: 12,73) (D) do gergelim cv. BRS seda aos 7 dias de semeadura.
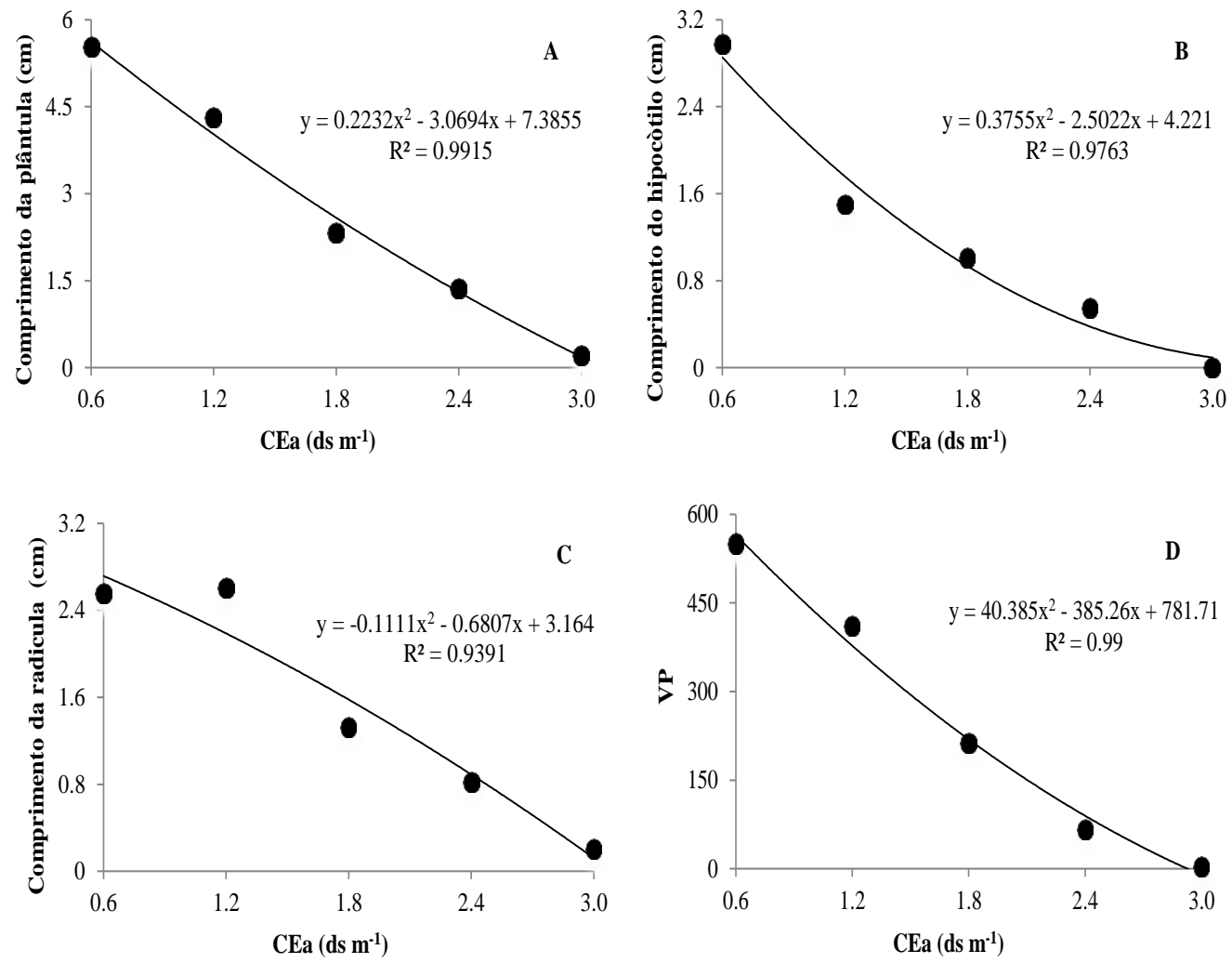

Essas variáveis de crescimento implicaram no vigor das plântulas (Figura 2D). Conforme os resultados, constata-se que o comprimento total da plântula e do hipocótilo são menores nas condutividades elétricas $1,8 \mathrm{dS} \mathrm{m}^{-1} ; 2,4 \mathrm{dS} \mathrm{m}^{-1}$ e $3,0 \mathrm{dS} \mathrm{m}^{-}$ ${ }^{1}$, confirmando o elevado efeito osmótico provocado pelos altos teores dos sais na água de irrigação. Azevedo et al. (2003) observaram que houve redução do comprimento do hipocótilo e total das plântulas de gergelim com o aumento dos níveis salinos da água. Este comportamento, provavelmente, ocorre em detrimento dos efeitos deletérios dos sais, que causam alterações na homeostase e afetam a qualidade fisiológica das sementes, resultando em uma maior desorganização das membranas celulares, o que afeta a qualidade e o vigor das sementes (NÓBREGA et al., 2018).

A massa fresca aérea e da radícula é inversamente proporcional á condutividade elétrica. A Figura 3A observa-se que a massa fresca aérea foi negativamente afetada pelo incremento salino na água, com maior intensidade nos tratamentos que apresentam maiores índices de sais. Normalmente, alta concentração de sais reduz o turgor celular, de modo que o baixo turgor celular inibe o alongamento e a divisão celular, diminuindo o crescimento e consequentemente a massa da planta (BEKELE et al., 2017).

A massa fresca radicular foi reduzida à medida que aumentou a condutividade elétrica da água de irrigação. Esses resultados estão de acordo com Bahrami e Razmjoo (2012) quando observaram que os níveis crescentes de sais na água de irrigação diminuem significativamente a massa seca da radícula e massa do cotiledôneo do gergelim.

Figura 3. Regressão da massa fresca aérea (A) e da radícula das plântulas (B), do gergelim cv. BRS seda em função da água salinizadas aos 7 dias da semeadura.
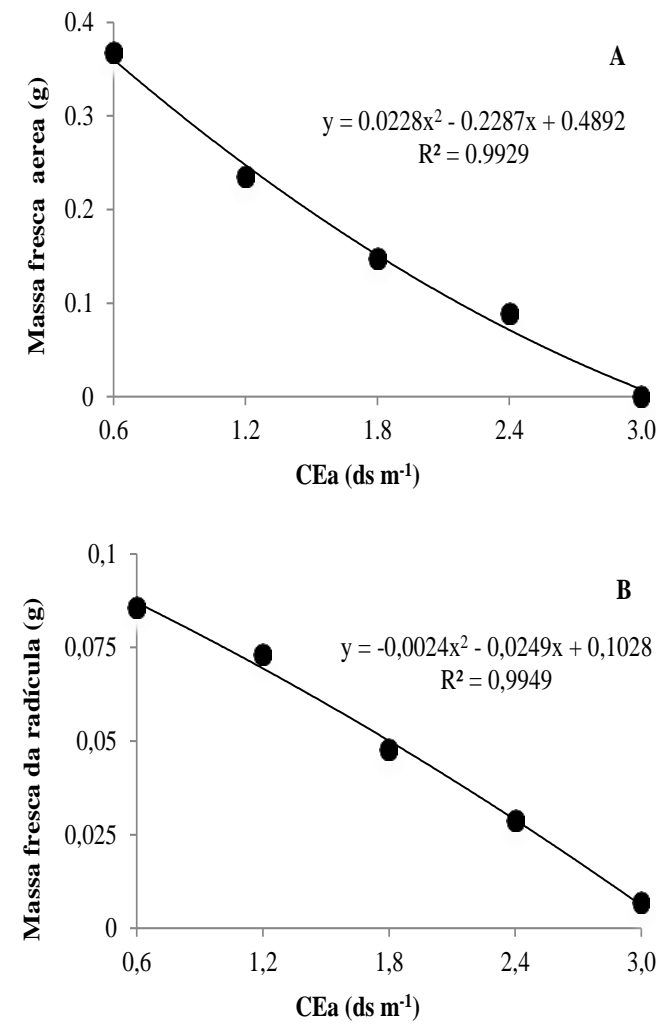


\section{CONCLUSÃO}

A cultivar de gergelim BRS seda possui capacidade de tolerância ao estrese salino à solução de até $1,8 \mathrm{dS} \mathrm{m}^{-1}$ na fase de germinação, no entanto, o crescimento da plântula reduz em mais de $50 \%$.

Não é recomendado uso da água com concentrações de sais a partir de $1,2 \mathrm{dS} \mathrm{m}^{-1}$ no estabelecimento da cultivar BRS seda.

\section{REFERÊNCIAS}

ABBASDOKHT, H.; ASHRAFI, E.; TAHERI, S. Effects of different salt levels on germination and seedling growth of sesame (Sesamum indicum L.) cultivars. Technical Journal of Engineering and Applied Sciences, v. 2, n. 10, p.309-313, 2012.

ANDRÉO-SOUZA, Y.; PEREIRA, A. L.; SILVA, F. F. S.; RIEBEIRO-REIS, R. C.; EVANGELISTA, M. R. V.; CASTRO, R. D.; DANTAS, B. F. Efeito da salinidade na germinação de sementes e no crescimento inicial de mudas de pinhão-manso. Revista brasileira de sementes, v. 32, n. 2 p. 083-092, 2010.

ANUPAMA, N.; MURALI, M.; SUDISHA J.; AMRUTHESH, K. N. Crude oligosaccharides from alternaria solani with bacillus subtilis enhance defense activity and induce resistance against early blight disease of tomato. Asian Journal of Science and Technology, v. 5, n. 7, p. 412-416, 2014.

AZEVEDO, M. R. Q. A.; ALMEIDA, F. A. C.; GOUVEIA, J. P. G.; AZEVEDO, C. A. V.; SILVA, M. M.; PORDEUS, R. V. Germinação e vigor no desenvolvimento inicial do gergelim: efeito da salinidade da água de irrigação. Revista Brasileira de Produtos Agroindustriais, v.5, n.2, p.167-172, 2003.

BAHRAMI H.; RAZMJOO J. Effect of salinity stress ( $\mathrm{NaCl})$ on germination and early seedling growth of ten sesame cultivars (Sesamum indicum L.). International Journal of AgriScience, v. 2, n. 6, p. 529-537, 2012.

BEKELE, A.; BESUFEKAD, Y.; ADUGNA, S.; YINUR, D. Screening of selected accessions of Ethiopian sesame (Sesame indicum L.) for salt tolerance. Biocatalysis and Agricultural

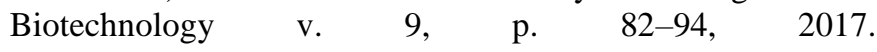
10.1016/j.bcab.2016.11.009

BRASIL, Ministério da Agricultura, Pecuária e Abastecimento. Regras para análise de sementes. Secretaria de Defesa Agropecuária. Brasília, DF: MAPA/ACS, 2009. 395 p.

DIAS, A. S.; LIMA, G. S.; GHEYI, H. R.; NOBRE, R. G.; SANTOS, J. B. Emergence, growth and production of sesame under salt stress and proportions of nitrate and ammonium. Revista Caatinga, v. 30, n. 2, p. 458-467, 2017. 10.1590/1983$\underline{21252017 \mathrm{v} 30 \mathrm{n} 221 \mathrm{rc}}$

DIAS, A. S.; LIMA, G. S.; GHEYI, H. R.; NOBRE, R. G.; FERNANDES, P. D.; SILVA, F. A. Trocas gasosas e eficiência fotoquímica do gergelim sob estresse salino e adubação com nitrato-amônio. Irriga, v. 23, n. 2, p. 220-234, 2018. 10.1590/1983-21252017v30n221rc

FAO, FOOD AND AGRICULTURE ORGANIZATION OF THE UNITED NATIONS - FAO (2018). FAOSTAT. Disponivel em: 〈http://www.fao.org/faostat/en/\#data/QC> Acesso em: 15/06/2020.

FERREIRA, D. F. Sisvar: A computer statistical analysis system. Revista Ciência e Agrotecnologia, Lavras, v. 35, n. 6, p. 1039-1042. 2011.

FURTADO, R. F.; MANO, A. R. O.; ALVES, R. C.; FREITAS, S. M.; MEDEIROS FILHO, S. Efeito da salinidade na germinação de sementes de algodão. Revista Ciência Agronômica, v. 38, n. 2, p. 224-227, 2007.

GRILO JUNIOR, J. A. S.; AZEVEDO, P. V. Crescimento, desenvolvimento e produtividade do gergelim brs seda na agrovila de canudos, em Ceará mirim (RN). Revista HOLOS, v. 2, n. 29, p. 19-33 2013.

GUIMARÃES, I. P.; OLIVEIRA, F. N.; VIEIRA, F. E. R.; TORRES, S. B. Efeito da salinidade da água de irrigação na emergência e crescimento inicial de plântulas de mulungu. Revista Brasileira de Ciências Agrárias, v.8, n.1, p.137-142, 2013. 10.5039/agraria.v8i1a2360

HOLANDA, J. S.; AMORIM, J. R. A.; FERREIRA NETO, M.; HOLANDA, A. C.; SÁ, F, V.S. Qualidade da água para irrigação In: Gheyi, H. R.; Dias, N. S.; Lacerda, C. F.; Gomes Filho, E. (2 eds.) Manejo da salinidade na agricultura: Estudos básicos e aplicados. Fortaleza - CE: INCTSal, 2016. cap. 4, p.35-50.

LIMA, M. F. P.; PORTO, M. A. F.; TORRES, S. B.; FREITAS, R. M. O.; Nogueira, N. W.; Carvalho, D. R. Emergência e crescimento inicial de plântulas de albízia submetidas à irrigação com água salina. Revista Brasileira de Engenharia Agrícola e Ambiental, v.19, n.2, p.106-112, 2015. 10.1590/1807-1929/agriambi.v19n2p106-112

MAGUIRE, J. D. Speed of germination: aid in selection and evaluation for seedling emergence and vigour. Crop Science, v. 2, n. 2, p. 176-177. 1962.

MEDEIROS, J. F. Qualidade de água de irrigação e evolução da salinidade nas propriedades assistidas pelo GAT nos Estados de RN, PB e CE. Dissertação de Mestrado. Universidade Federal da Paraíba, Campina Grande. p. 173, 1992.

MESQUITA, J. B. R.; AZEVEDO, B. M.; CAMPELO, A. R.; FERNANDES, C. N. V.; VIANA, T. V. A. Crescimento e produtividade da cultura do gergelim (Sesamum indicum L.) sob diferentes níveis de irrigação. Irriga, Botucatu, v. 18, n. 2, p. 364-375, 2013. 10.15809/irriga.2013v18n2p364

NÓBREGA, J. S.; LOPES, K. P.; SANTOS, J. B.; PAIVA, F. J. S.; SILVA, J. G.; LIMA, G. S. Quality of sesame seeds produced under soil salinity levels. Pesquisa agropecuária tropical, v. 48, n. 3, p. 280-286, 2018. 
POSSAS, J. M. C.; NASCIMENTO, R.; MAIA FILHO, F. C. F.; NASCIMENTO, D. A. M.; ALENCAR, A E. V. Efeito da salinidade na germinação de sementes de pinhão manso. Revista Verde de Agroecologia e Desenvolvimento Sustentável, v 9, n. 4, p. 184-188, 2014.

PRISCO, J. T.; GOMES FILHO, E.; MIRANDA, R. S. Physiology and biochemistry of plants growing under salt stress. In: GHEYI, H. R. et al. (Ed.). Manejo da salinidade na agricultura: Estudos básicos e aplicados. Fortaleza: INCTSal, p. 163-180, 2016.

SANTOS, C. A.; SILVA, N. V.; WALTER, L. S.; SILVA, E. C. A.; NOGUEIRA, R. J. M. C. Germinação de sementes de duas espécies da caatinga sob déficit hídrico e salinidade. Pesquisa florestal Brasileira, v. 36, n. 87, p. 219-224, 2016. 10.4336/2016.pfb.36.87.1017

SOLTANI, A.; GHOLIPOOR, M.; ZEINALI, E. Seed reserve utilization and seedling growth of wheat as affected by drought and salinity. Environmental and Experimental Botany, v. 55, n. 01/02, p. 195-200 2006. 10.1016/j.envexpbot.2004.10.012

SUASSUNA, J. F.; FERNANDES, P. D.; BRITO, M. E. B.; ARRIEL, N. H. C.; MELO, A. S; FERNANDES, J. D. Tolerance to Salinity of Sesame Genotypes in Different Phenological Stages. American Journal of Plant Sciences, v. 8, p.1904-1920, 2017. 10.4236/ajps.2017.88129 